\title{
Recognizing the Traits of Giftedness in Minorities as They Impact Identification
}

\author{
Kathie Carwile Morgan \\ School of Education, Liberty University
}

\begin{abstract}
This article is a review of continuing research to examine whether expectations and perceptions of gifted behaviors for giftedness are influenced by the ethnicity of the evaluator. Is it possible that the indicator behaviors of various ethnicities are not recognized by untrained observers from outside the ethnic culture of that student? Are expectations and the view of giftedness from the perspective of one's own personal ethnicity the reason for lower percentages of minority students in gifted and talented programs across the United States? This research examines observer perceptions of giftedness based upon ethnicity, the traits identified as indicators for giftedness expressed by leaders (teachers, administrators, parents, and community leaders) from within their own particular ethnicity.
\end{abstract}

\section{Introduction}

According to the National Center for Educational Statistics' Digest of Educational Statistics: 2010, the public school system of the United States recognizes $3,236,990$ students as gifted and talented from of a total student population of $49,315,842$; or $6.6 \%$ on the total student enrollment for elementary and secondary schools based upon the most recent year for available statistics, 2006. Within the identified gifted and talented population $68 \%$ are Caucasian $(2,191,210)$, 9\% are Black $(296,150), 13 \%$ are Hispanic (414,060), 9\% are Asian/Pacific Islanders, and 1\% Native American/Alaskan Native students $(31,360)$. This is compared to the race/ethnicity enrollment percentages in the elementary and secondary public school system of 54.9\% Caucasian, 17\% Black, 21.5 $\%$ Hispanic, 5\% Asian/Pacific Islander and $1.2 \%$ American Indian/Alaska Native. These numbers continue to baffle and cause concern among those who believe that giftedness is a universal cross- cultural phenomenon and that identification of enrolled students should correlate with the percentages that ethnicity represents in the general population. Why is it that we continue to see a lag in the number of Black and Hispanic students that qualify for the gifted and talented program? Is there really racial bias, as many have concluded? Is it that poverty can stymie giftedness? Or could it be that we just don't recognize the giftedness exhibited by students from cultures different than our own? That is the position of this research. Research does indicate that the education system of the United States sometimes fails in identifying the academically gifted outside the majority culture [5]. Researchers report that students with exceptional abilities, that are perhaps overshadowed by their racial or cultural differences or poverty, and are often overlooked for inclusion in programs for the gifted [12]. Definition and identification of giftedness among these students is often contradictory, ineffective, and insufficient [12].

There are many previously identified causes for this underrepresentation of minority students, social and contextual (poverty, expectations within the family and community,) that are not within the scope of the school system's provision to correct [2]. But there is the possibility that ignorance of another culture, unintentional bias, and misreading of cultural traits by those in charge of the identification of the gifted and talented can present a negative effect on the referral of minority students into this program. The possibility of this cultural phenomenon should, indeed, must be addressed by the educational community [2].

Teachers generally want the very best for their students. Recommendation for a special program, in this case the gifted and talented program, is not a reward handed out by teachers for towing the line. Teachers know that high scores on ability or achievement test may indicate that a student is gifted. They often pick up on a student that exhibits outstanding ability in a particular subject area or writes well. It is the child that presents out of the realm of expectation that is often missed in the educational setting. The child that challenges authority, is too loud and authoritative, the child that daydreams, doodles, and misses assignments, that one that creates problems and is an annoyance in the classroom can often be missed. Yet, these very characteristics that are challenging and bothersome in the classroom may be the very behaviors that the cultural community from which the student comes that are valued and rewarded. This study examines the traits identified by members of the ethnic/cultural (Caucasian, Black, Hispanic, Asian/Pacific Islanders and American Indian/Alaskan Native) as those that they would expect to see in a gifted child of their own ethnicity. 


\section{Method}

Volunteer participants in this study identified their work position, degree level and their own ethnicity. They were given questionnaires and asked to read two explanatory models and to respond to the two following questions:

1. What are the traits that are recognized in a child of your own ethnicity that are indicators to you that the child is gifted?

2. Do you believe that a teacher from a different ethnicity would recognize and identify the child? Why or why not?

\section{Participants}

A total of 75 adults filled out questionnaires. All respondents, at this point in the study, were adults pursuing an advanced degree at either master's or doctoral level. The respondents were attending weekend classes in order to satisfy residency requirements for their particular degree program. The respondents were from various states and many vocations, although they were all seeking a degree in either education or counseling. Forty-eight of the respondents identified their own ethnicity as Caucasian, 13 respondents self-identified as Black, 4 respondents self-identified as Hispanic, 2 respondents self-identified as Asian/Pacific Islander and 2 respondents selfidentified themselves as American Indian, 6 respondents did not identify ethnicity or race and were eliminated from the study.

\section{Instrument}

The two question response form for the questionnaire introduced the idea of what was to be considered by presenting a two-model scenario where a child of the same ethnicity as the respondent was observed by an adult (not the parent) in both a formal and informal environment. In both models the child was portrayed as having exceptional behaviors that stood out to the examiner. These models were to impress on the respondents that the response was to be for a child of their own ethnicity inside or outside the educational school environment.

The questions on the form were:

Question 1. What are the traits that are recognized in a child of your own ethnicity that are indicators to you that the child is gifted? This can be within any area at all: personality, affective or emotional behavior, physical feats, cognitive achievement, psychological behaviors, art, sports, insight, etc.

Question 2. Do you believe that a teacher of a different ethnicity would recognize the behavior and identify the child? Why or why not?

\section{Data Collection and Analysis}

The questionnaire was presented to the adults during a weekend meeting of several graduate level classes. The questionnaire took 5 to 10 minutes to complete. The questionnaires were offered to professors to offer to the graduate students. Neither the professors or students were compelled to complete the questionnaire; it was voluntary.

Analysis of the responses was done based upon the personal ethnicity identified by the respondent. The questionnaires were analyzed using qualitative data analysis. The responses were first separated into the ethnicities identified on the National Center for Educational Statistics, those being: Caucasian, Black, Hispanic, Asian/Pacific Islander, and American Indian/Alaska Native. Six questionnaires were eliminated due to non- response on personal ethnicity.

Once the groups were compiled, the responses and traits listed were noted and counted for frequency of occurrence and listed in that order.

\section{Findings}

Question 1. What are the traits that are recognized in a child of your own ethnicity that are indicators to you that the child is gifted?

Forty-eight respondents identifying themselves as Caucasian identified the following traits as indicative of giftedness within their own ethnicity and would be recognized in or outside a school environment by themselves in the following order:

Cognitive ability Verbal ability

Motivation/passion/drive in a particular area Concentration/Focus/Task oriented Critical thinking Creative ability Kinesthetic/Spatial ability Ability to grasp concepts /

Insightfulness Curiosity Social Skills/Maturity

Thirteen respondents identifying themselves as Black identified the following traits as indicative of giftedness within their own ethnicity and would be recognized in or outside a school environment by themselves in the following order: 
Self-expression ability Communication skill Kinesthetic Ability/Imitation(art/music/sports ability)

Cognitive ability

Creative thinking skill, identified by Several as "out of the box" thinking Concentration/Focused independent learner Precocity/Initiative Inquisitive/Curious Ability to grasp concepts / Insightfulness Empathy/Social skill

The 4 respondents identifying themselves as Hispanic identified the following traits as indicative of giftedness within their own ethnicity and which would be recognized in or outside a school environment by themselves in the following order:

Artistic/Kinesthetic ability (art/music/sports)

Cognitive ability/Achievement Ability to grasp concepts I

Insightfulness Logic Leadership

The 2 respondents identifying themselves as Asian identified the following traits as indicative of giftedness within their own ethnicity and would be recognized outside a school environment by themselves in the following order:

Cognitive ability (test scores, exceptional skill, brain games)

Kinesthetic ability (specifically musical ability)

Attention to task/focus Verbal skill Leadership

Respectfulness

Social skill

The 2 respondents identifying themselves as American Indian identified the following traits as indicative of giftedness within their own ethnicity and would be recognized outside a school environment by themselves in the following order:

Verbal/Communication skill Problem analysis/synthesis

Question 2. Do you believe that a teacher from a different ethnicity would recognize the behavior and identify the child as gifted? Why or why not? Overwhelmingly the respondents acknowledged that a teacher from another ethnicity could and would identify a gifted child exhibiting the listed traits, many stating emphatically in the response that traits of giftedness were obvious and not related to ethnicity. However, six of the respondents noted that they believed that cultural behaviors and traits could be misread or misinterpreted by a teacher unfamiliar with gifted education or without exposure to the particular ethnicity.

\section{Discussion}

Examination of the listing of indicators recognized by various ethnicities causes one to consider the traits that are valued in each different ethnic culture and community. While we espouse the melting pot that the United States is supposed to be, we still exist for the most part, in our individual communities and we are most often surrounded by those that are just like ourselves. While ethnicities work together, attend the same events, and children from different ethnicities attend school together, each individual carries the traits and behaviors that are valued and rewarded within their own small community. Some of those traits go unrecognized by those unfamiliar with that community.

Teachers are very good at recognizing exceptional cognitive ability. Grades and test scores and extremely acute verbal abilities are quickly recognized, identified, and rewarded. The very verbal ability which may be rewarded within the ethnic/cultural environment and a sign of giftedness, will, if used assertively or aggressively to challenge a teacher or another student at school, be viewed as a problematic behavior rather than an indicator of great verbal ability and a gift. The child that is very insightful, an independent thinker, and independent worker, behaviors that are highly valued in all cultures, can be viewed as mood, uncooperative, resistant to working with the group, and argumentative. Students that exhibit many of the identified behaviors would probably not be recognized in many classrooms. While teachers may want to recognize all students and give them the respect and assistance that they deserve, those same teachers are charged with instructing large groups of students and one student that displays characteristics that are unlike those of the majority creates problems and takes time away from others. Problems are rarely looked on as gifts or talents. The indicators identified by these respondents create recognition that even with the best intentions teachers don't recognize many of the behaviors that represent giftedness. It is time to reexamine the indicators and train those charged with identification so that each ethnicity will be completely represented by the brightest minds.

\section{Limitations}

The primary limitation of this study is the limited number of respondents from the various ethnicities. It would be beneficial to have a much greater number of respondents from each ethnicity. Ideally it would be best to have equal numbers of each racial/ethnic group.

The respondents were all highly educated graduate students seeking either Master's level or Doctoral level 
degrees in Education or Counseling. A more diverse group of respondents may yield different results.

\section{Conclusions}

The majority of students admitted into a gifted and talented program are initially identified and referred by a classroom teacher. Based on this limited study it would seem that while we believe that teachers know giftedness when they see it, there is evidence to support the need for additional training for educators and even a call for examination of the indicators and characteristics of the gifted within ethnicities . Judging from the responses of the different ethnic groupings, there seem to be some unique qualities that those within that culture view as indicators of giftedness that have not previously been recognized. The expression of these unique characteristics calls for reexamination of the identification process for those that are operating from a cultural minority. Recommendations for new indicators for the gifted and talented programs and training for those responsible for identification of the gifted are in order. Further investigation of these findings and the identification of traits and indicators for giftedness is needed. Additionally, teachers must be trained to see beyond their own limited cultural experience and recognize even that behavior that seems to be most challenging may be a valued and gifted behavior in the student's community.

\section{References}

[1] Committee on Minority Representation in Special Education. M. Suzanne Donovan and Christopher T. Cross, Editors, (2002). Minority students in special and gifted education. National Research Council.

[2] Donovan, M. S., \& Cross, C. T. (2002). Minority students in special and gifted education. Washington, DC: National Academy Press.

[3] Elhoweris, H. (2008). Teacher judgment in identifying gifted/talented students. Multicultural Education, v. 15, n. 3,pgs.35-38.

[4] Ford, D. Y. (1998). The underrepresentation of minority students in gifted education: Problems and promises in recruitment and retention. The Journal of Special Education, 32 (1),4-14.

[5] Ford, D. Y., Harris, J. J., Tyson, C. A., \& Trotman, M. F. (2002). Beyond deficit thinking: Providing access for gifted African American students. Roeper Review, 24, 5258.

[6] Henson, S. (2006). The evolution of creativity, giftedness, and multiple intelligences: An interview with Ellen Winner and Howard Gardner. Roeper Review.
[7] Kyburg, R., Hertberg-Davis, H. \& Callahan, C. (2007). Advancement placement and international baccalaureate programs: Optimal learning environments for talented minorities? Journal of Advanced Academics, v18 n2 p172-215

[8] Lawrence, B. (2009). Rural gifted education: A comprehensive literature review. Journal for the Education of the Gifted Vol. 32, No. 4, pp.461-494. Waco, TX: Prufrock Press, Inc.

[9] Patton, J.M., Prillaman, D., \& VanTassel-Baska, J. (1990). The nature and extent of programs for the disadvantaged gifted in the United States and Territories. Gifted Child Quarterly, 34(3), 94-101. [See Vol. 6, p.141.]

[10] Patton, James M. (1992). Assessment and identification of African-American learners with gifts and talents. The Free Library. (1992).

[11] Tavegia, B. (2005). The experiences of parents of gifted African American children: a phenomenological study. Roeper Review.

[12] Van Tassel Baska, J., Patton, J., \& Prillaman, D. (1989). Disadvantaged gifted learners at risk for educational attention. Focus on Exceptional Children, 22(3), 1-15. 